\title{
Power Flow Analysis of Abule-Egba 33-kV Distribution Grid System with real network Simulations.
}

\author{
${ }^{1}$ Ademola Abdulkareem, ${ }^{2}$ C.O.A. Awosope, ${ }^{3}$ H.E. Orovwode, ${ }^{4}$ A.A. Adelakun \\ Department of Electrical and Information Engineering, College of Science and Technology, \\ Covenant University, Ota, Nigeria.
}

\begin{abstract}
In order to ascertain that an electric power is economically transferred over the grid system with maximum efficiency and reliability at virtually fixed voltage and frequency to consumers, it becomes imperative to carry out power flow studies. This study presents a model of an electrical distribution grid on a computer system for simulation. Hence the research work models and simulates a distribution grid using the "ETAPS" software. By making a model of the distribution network, the value of real and reactive powers and voltage magnitudes in the whole network can be observed. The simulation results obtained from the existing condition of 33-kV Ota transmission network and the 11/0.415-kV Yusuf and Abule-Iroko injection substations indicate that 15 feeder pillars have low voltage violations. To solve the problem of voltage violations, shunt capacitor compensators were placed at affected locations, resulting in a network with improved voltageprofile.
\end{abstract}

Keywords: ETAP software, power flow, shunt capacitor, simulation, voltage magnitude

\section{Introduction}

Power load-flow analysis is executed to find the sensitivity of feeder status with variation of power loading, conductor length, and total capacity of distribution transformers. They are used to ensure that electrical power transfer from generator to consumers through the grid system is stable, reliable and economical. The major goal of a power flow study is to investigate that all busbars voltage are within specified limits and that the flow of reactive power is reasonable as to ensure that acceptable quality of service could be provided for the consumers. The planning, design and operation of power systems require load flow computations to analyse the steady - state performance of the power system under various operating conditions and to study the effects of changes in equipment configuration. These load flow studies can be performed using computer programs designed specifically for this purpose [1].

To overcome the computational problems of power-flow solution using load-flow iterative technique Newton Raphson and Gauss Siedel as contained in [2], one best method to see a system is by making model and doing simulation. To make a good simulation, it needs a model based on real condition. The making of this model must be based on real and valid data so the model can represent real condition [3]. By using simulation, the expected result can be seen in every point and changes can be made in the model to improve the weak points. Model is a representation of a system and electricity distribution is also a system. So in this paper, the modeling and simulation of electrical distribution grid on a Computer system are conducted with the aim of improving the voltage profile of some weak feeder pillars via the outputs of VAR compensating devices and saves cost by procuring strategies to carrying out security dispatch operation on the grid so as to cater for contingencies in the electrical grid when they occur.

\section{Abule-Egba Distribution Network}

The one-line diagram of Abule-Egba distribution network is shown in Fig. 1 The utility company has multi-voltage systems with substations and transformer between each of these levels. It consists of one-single 33-kV Ota transmission line feeding Abule-Iroko and Yusuf 11-kV injection substations. The utilities which are involved in the distribution of electricity are the 33-kVOta transmission lines:1 X 7.5 MVA 33/11kV, T/S 2 X 40MVA $33 / 11 \mathrm{kV}$ and 2x1.5MVA 33/11kV transformers [4]

- The 11-kV Abule-Iroko Injection Substation: 12 nos of $11 / 0.415 \mathrm{kV}$ distribution transformers rated 6x500KVA, 5x300KVA and 1x50KVA.

- The 11-kV Yusuf Injection Substation: 28 nos of $11 / 0.415 \mathrm{kV}$ distribution transformers rated as- 20x500 KVA, 6x300KVA and 2x50KVA. 


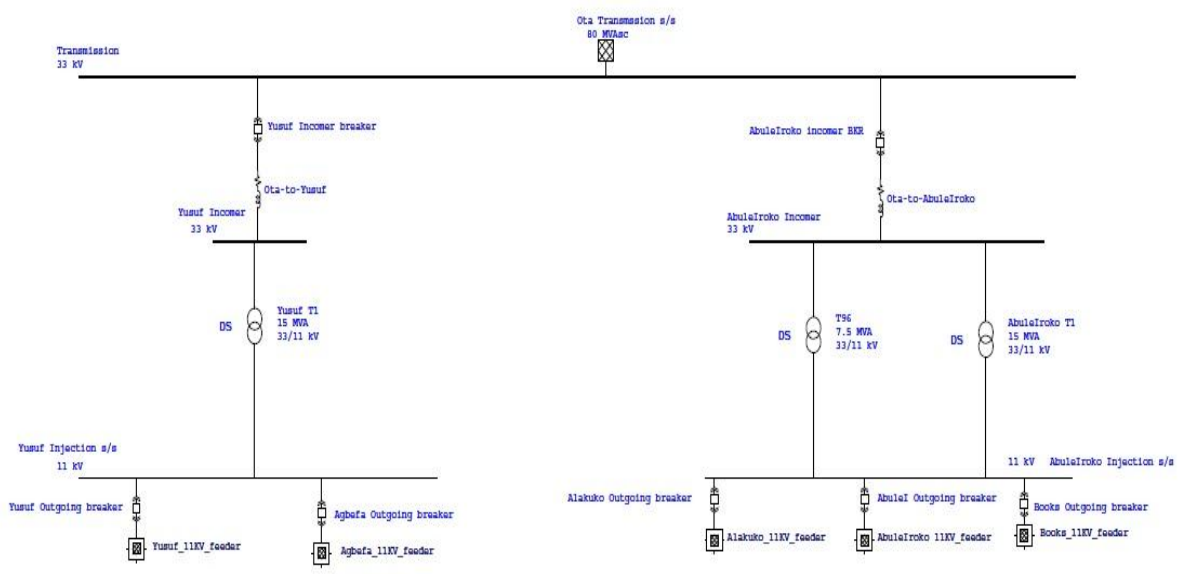

Figure 1: One-line diagram of AbuleEgba distribution grid.

\section{Steady-State Component Model}

As earlier stated, power-flow studies provide the planning engineer with information concerning the system when it is operating under normal stead- state conditions; hence the mathematical models of the components required are a per phase model that applies under normal steady-state conditions.

\subsection{The Per Unit (P.U) Model of Synchronous Generator}

This is the main energy converter in an electric power system. It has the major responsibility of converting mechanical turbine power into electrical power at a desired frequency and voltage. Since in powerflow studies, we are interested only in the steady-state power output of the synchronous generator, obtained knowing merely terminal voltage and current, then we need only to model the synchronous generator as a constant voltage source.

From "Synchronous Generators" [5], in the model of a synchronous generator which is important in the supply of power especially through the voltage regulator bus we have:

$\mathrm{V}_{\mathrm{b}}=\mathrm{V}_{\mathrm{n}}$-Peak stator phase nominal voltage.

$\mathrm{I}_{\mathrm{b}}=\mathrm{I}_{\mathrm{n}}$-Peak stator phase nominal current.

$\mathrm{S}_{\mathrm{b}}=3 \mathrm{~V}_{\mathrm{n}} \mathrm{I}_{\mathrm{n}}-$ Nominal apparent power.

$\omega_{\mathrm{b}}=\omega_{\mathrm{m}}-$ Rated electrical angular speed $\left(\omega_{\mathrm{m}}=\mathrm{p}_{1} \Omega_{\mathrm{m}}\right)$

\subsection{Model of a Transformer}

Model of a transformer which is the major distribution utility in the distribution grid is obtained from the equivalent circuit of Fig. 2 shown below:

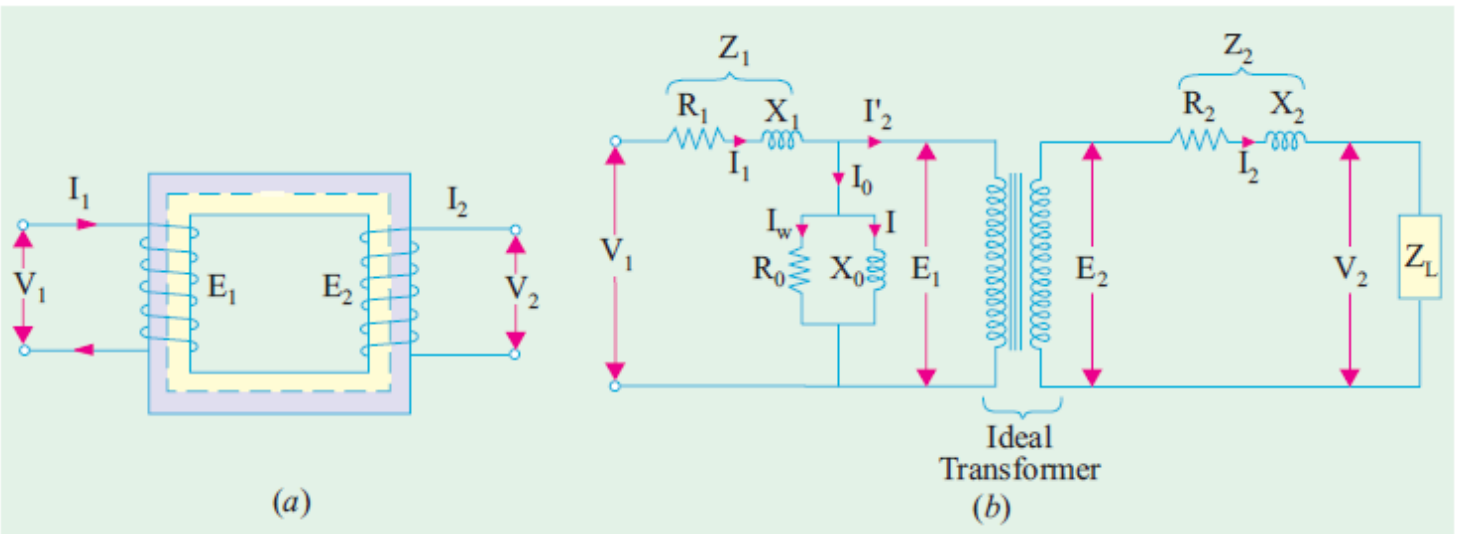

Figure 2: Equivalent circuit of a transformer: (a) A pictorial representation of a transformer From the equivalent circuit we define the following parameters 
$\mathrm{V}_{1}=$ The primary voltage of the transformer

$\mathrm{R}_{1}=$ The resistance of the primary circuit

$\mathrm{X}_{1}=$ The reactance of the primary circuit

$\mathrm{I}_{2}=$ The referred secondary current

$\mathrm{I}_{0}=$ The excitation current

$\mathrm{I}_{1}=$ Primary current

$\mathrm{R}_{0}=$ The resistance of the excitation circuit

$\mathrm{X}_{0}=$ The reactance of the excitation circuit

$\mathrm{I}_{\mathrm{w}}=$ The loss component of the excitation current

$\mathrm{I}=$ The magnetizing component of the excitation current

$\mathrm{E}_{1}=$ Primary induced EMF

$\mathrm{E}_{2}=$ Secondary induced EMF

$\mathrm{R}_{2}=$ Resistance of the secondary circuit

$\mathrm{X}_{2}=$ Reactance of the secondary circuit

$\mathrm{V}_{2}=$ Terminal voltage

$\mathrm{I}_{2}=$ Secondary current

$\mathrm{V}_{2}=$ Terminal voltage

$\mathrm{Z}_{\mathrm{L}}=$ Load impedance

\subsection{Model of Distribution Loads}

Distribution loads are available in two forms which are:

- Spot/Point loads and;

- Distributed loads.

\subsubsection{Sport/Point Loads}

From "Load flow solution of unbalanced radial distribution" [6], it is assumed that all loads draw real and complex power $(S L q=P L q+j Q L)$ and that all three-phase loads are star and delta connected and all doubleand single-phase loads are connected between line and neutral and line to line respectively[5]. Figs 3 and 4 below show the graphic picture of a both star and delta connected loads.

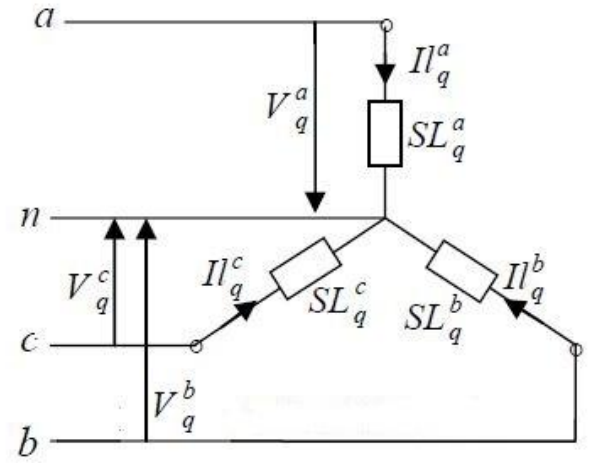

Fiure 3: Star-connected load.

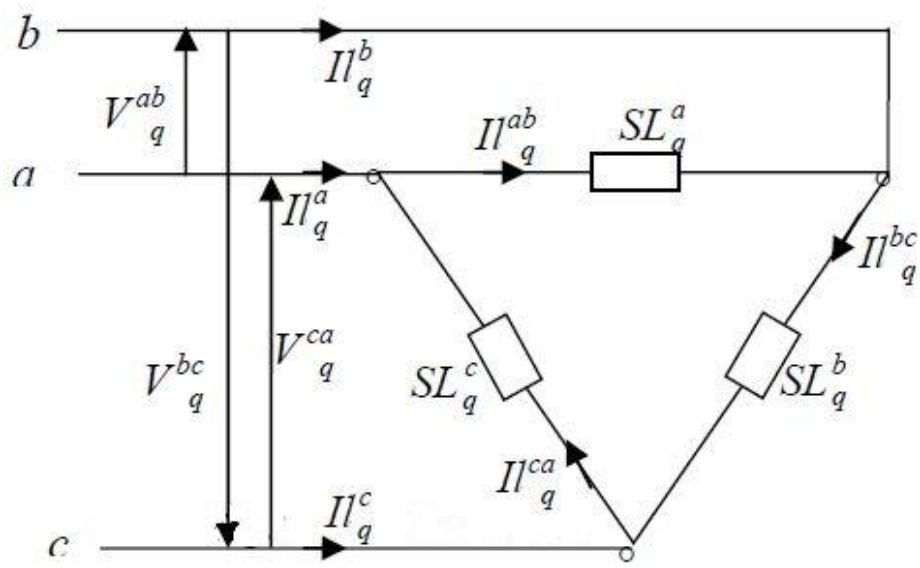

Figure 4: Delta-connected load. 
From Fig. 4 above, $\mathrm{SL}_{\mathrm{q}}{ }^{\mathrm{a}}, \mathrm{SL}_{\mathrm{q}}{ }^{\mathrm{b}}, \mathrm{SL}_{\mathrm{q}}{ }^{\mathrm{c}}$ can be of different values or even zeros. In fact, double- phase and singlephase loads are modeled by setting the values of the complex power of the non-existing phases to zero [6]. In the case of three-phase loads connected in star or single- phase loads connected line to neutral, the load current injections at the $q$ th bus can be given by:

$$
\left[\begin{array}{c}
I l_{q}^{a} \\
I l_{q}^{b} \\
I l_{q}^{c}
\end{array}\right]=\left[\begin{array}{l}
\left(\frac{S L_{q}^{a}}{V_{q}^{a}}\right)^{*} *\left|V_{q}^{a}\right|^{n} \\
\left(\frac{S L_{q}^{b}}{V_{q}^{b}}\right)^{*} *\left|V_{q}^{b}\right|^{n} \\
\left(\frac{S L_{q}^{c}}{V_{q}^{c}}\right)^{*} *\left|V_{q}^{b}\right|^{n}
\end{array}\right]=\left[\begin{array}{l}
\left(\frac{P L_{q}^{a}+j Q L_{q}^{a}}{V_{q}^{a}}\right)^{*} *\left|V_{q}^{a}\right|^{n} \\
\left(\frac{P L_{q}^{b}+j Q L_{q}^{b}}{V_{q}^{b}}\right)^{*} *\left|V_{q}^{b}\right|^{n} \\
\left(\frac{P L_{q}^{c}+j Q L_{q}^{c}}{V_{q}^{c}}\right)^{*} *\left|V_{q}^{c}\right|^{n}
\end{array}\right]
$$

The current injections at the $q$ th bus for three-phase loads connected in delta or single-phase loads connected line to line can be expressed by

$$
\begin{aligned}
& {\left[\begin{array}{c}
I l_{q}^{a} \\
I l_{q}^{b} \\
I l_{q}^{c}
\end{array}\right]=\left[\begin{array}{l}
\left(\frac{S L_{q}^{a b}}{V_{q}^{a b}}\right)^{*} *\left|V_{q}^{a b}\right|^{n}-\left(\frac{S L_{q}^{c a}}{V_{q}^{c a}}\right)^{*} *\left|V_{q}^{c a}\right|^{n} \\
\left(\frac{S L_{q}^{b c}}{V_{q}^{b c}}\right)^{*} *\left|V_{q}^{b c}\right|^{n}-\left(\frac{S L_{q}^{a b}}{V_{q}^{a b}}\right)^{*} *\left|V_{q}^{a b}\right|^{n} \\
\left(\frac{S L_{q}^{c a}}{V_{q}^{c a}}\right)^{*} *\left|V_{q}^{c a}\right|^{n}-\left(\frac{S L_{q}^{b c}}{V_{q}^{b c}}\right)^{*} *\left|V_{q}^{b c}\right|^{n}
\end{array}\right]} \\
& =\left[\begin{array}{l}
\left(\frac{P L_{q}^{a b}+j Q L_{q}^{a b}}{V_{q}^{a b}}\right)^{*} *\left|V_{q}^{a b}\right|^{n}-\left(\frac{P L_{q}^{c a}+j Q L_{q}^{c a}}{V_{q}^{c a}}\right) *\left|V_{q}^{c a}\right|^{n} \\
\left(\frac{P L_{q}^{b c}+j Q L_{q}^{b c}}{V_{q}^{b c}}\right)^{*} *\left|V_{q}^{b c}\right|^{n}-\left(\frac{P L_{q}^{a b}+j Q L_{q}^{a b}}{V_{q}^{a b}}\right)^{*} *\left|V_{q}^{a b}\right|^{n} \\
\left(\frac{P L_{q}^{c a}+j Q L_{q}^{c a}}{V_{q}^{c a}}\right)^{*} *\left|V_{q}^{c a}\right|^{n}-\left(\frac{P L_{q}^{b c}+j Q L_{q}^{b c}}{V_{q}^{b c}}\right)^{*} *\left|V_{q}^{b c}\right|^{n}
\end{array}\right]
\end{aligned}
$$

Equations (5) and (6) represent a generalized model for star and delta load models, where $\mathrm{n}$ is defined as follows:

$\mathrm{n}=0$ Constant power

$\mathrm{n}=1$ Constant current

$\mathrm{n}=2$ Constant impedance [6].

Most of the time point or spot loads are usually hung or mounted on poles where they feed companies and business centres.

\subsubsection{Modeling of Distributed Loads}

According to [6], in the unbalanced distribution system, loads can be uniformly distributed along a line. When the loads are uniformly distributed, it is not necessary to model each and every load in order to determine the voltage drop from the source end to the last loads. From D. Shirmohammadi [7], the total distributed load on each phase of a line section is lumped half-half at the line sections of two end buses. The load at bus $\mathrm{p}$ and bus $\mathrm{q}$ 
can be modelled as spot loads shown in the Fig. 4. Depending on the spot load type, equations (5) and (6) are used to calculate the load current at respective $p$ and $q$ buses. The diagram of distributed loads is seen in fig. 5 while the spot load equivalent is seen in Fig 5.

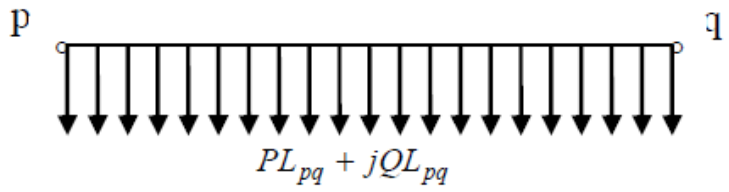

Figure 4: Diagram of a distributed load equivalent.

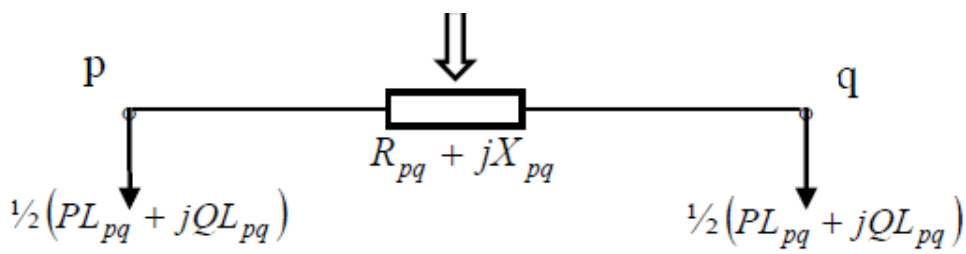

Figure 5: Diagram of a spot load equivalent.

The sections to be modeled are those which draw power from Ota transmission station. The list of the injection substations under Abule-Egba distribution and connected to Ota transmission are

- Abule-Iroko injection substation

- Yusuf injection substation

Each of these injection substations contains at least two feeders. Below are the explanation of the derived components and what they're modeled with:

- The 33-kV Ota transmission feed is modeled by a power grid which is an interfacing point to the power grid whose voltage and frequency are supported by a larger system and unlikely to change. It is valid to assume this equivalent machine has a constant internal voltage source and an infinite inertia. Thus the power grid is modeled in PowerStation with the following Thevenin's equivalent:

$E i$

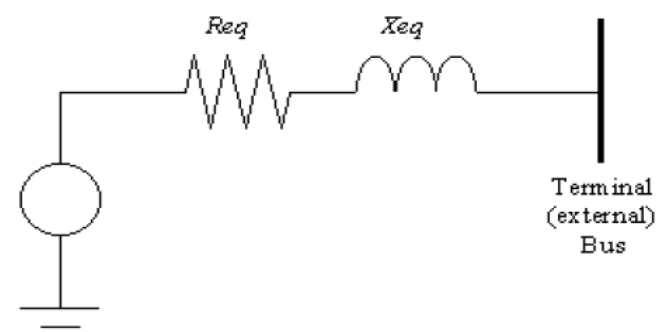

Figure 6: Thevenin's equivalent of the power grid.

From Fig. 6 above, Eiis calculated from the initial terminal bus voltage and Reqand Xeqare from positive sequence $R$ and $X$ of the Power Grid Editor, as shown in Fig. 7 below:

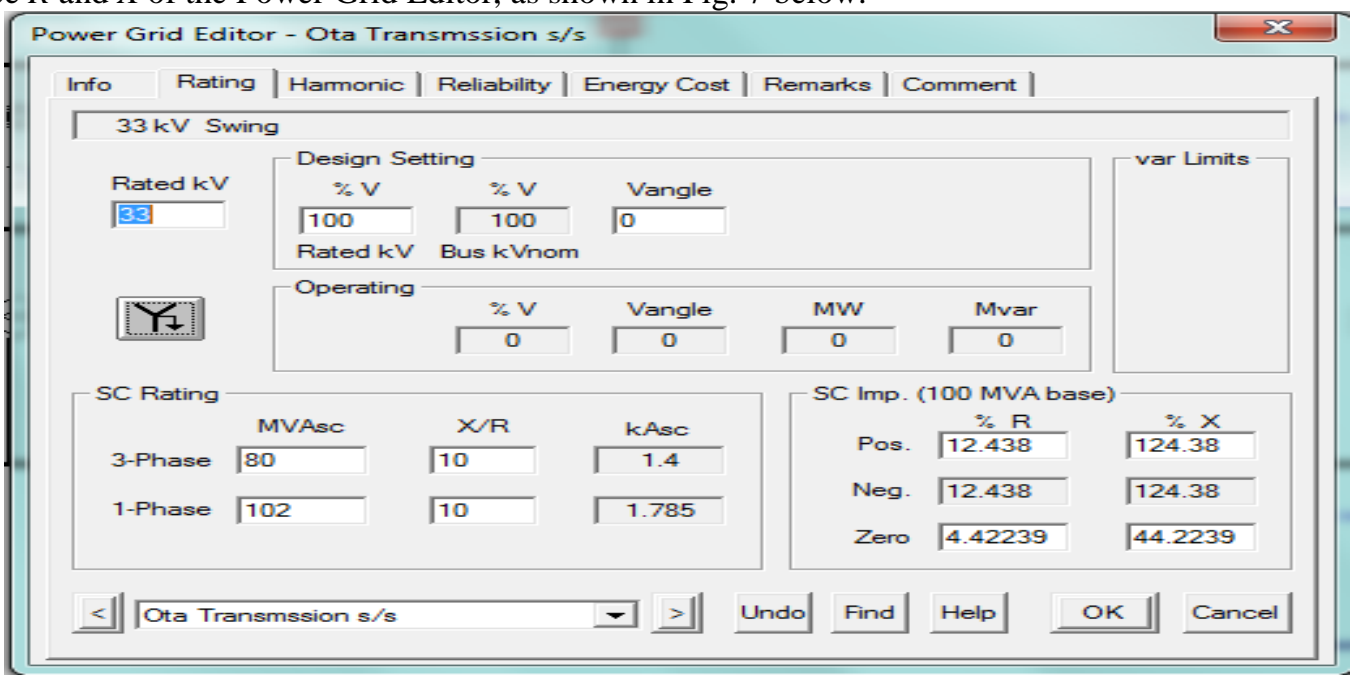

Figure 7: A representation of the power grid utility 
- The feeder pillars: These are represented by bus bars as illustrated from the coming diagrams.

- The Lumped loads: These are loads which represent the dynamic nature with which the loads tapped from the transformers are being utilized. For companies which run on machine, their motor loads exceed their static loads and the power flow is computed at that.

The $\mathrm{kV}$ taps on the parameter section of the modeled transformer are similar to those on the name plate in Fig. 8 below:

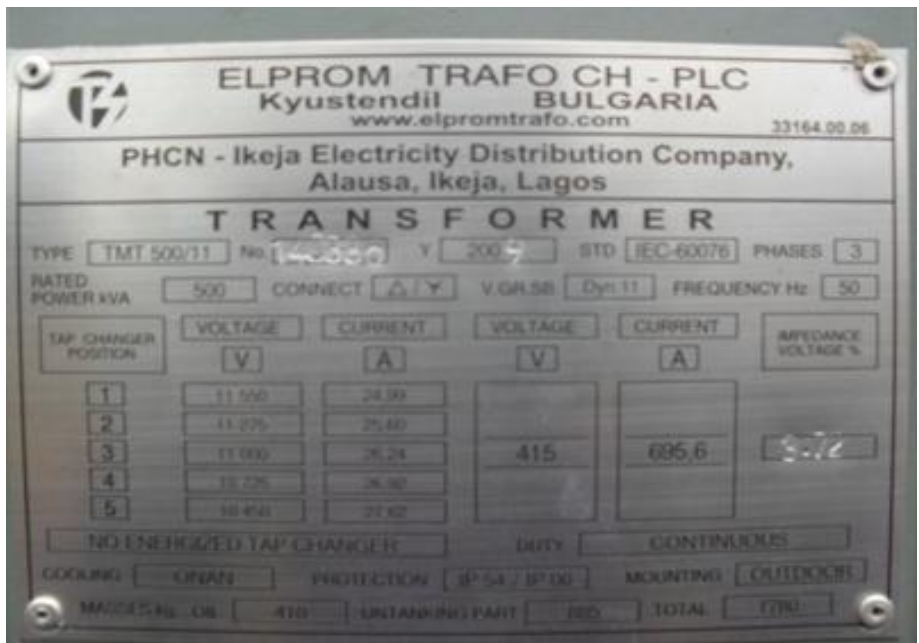

Figure 8: Transformer particulars

The transmission line parameters for the lines which link or connect Ota distribution to both YUSUF and ABULE IROKO injection substations are given in Fig. 9 below:

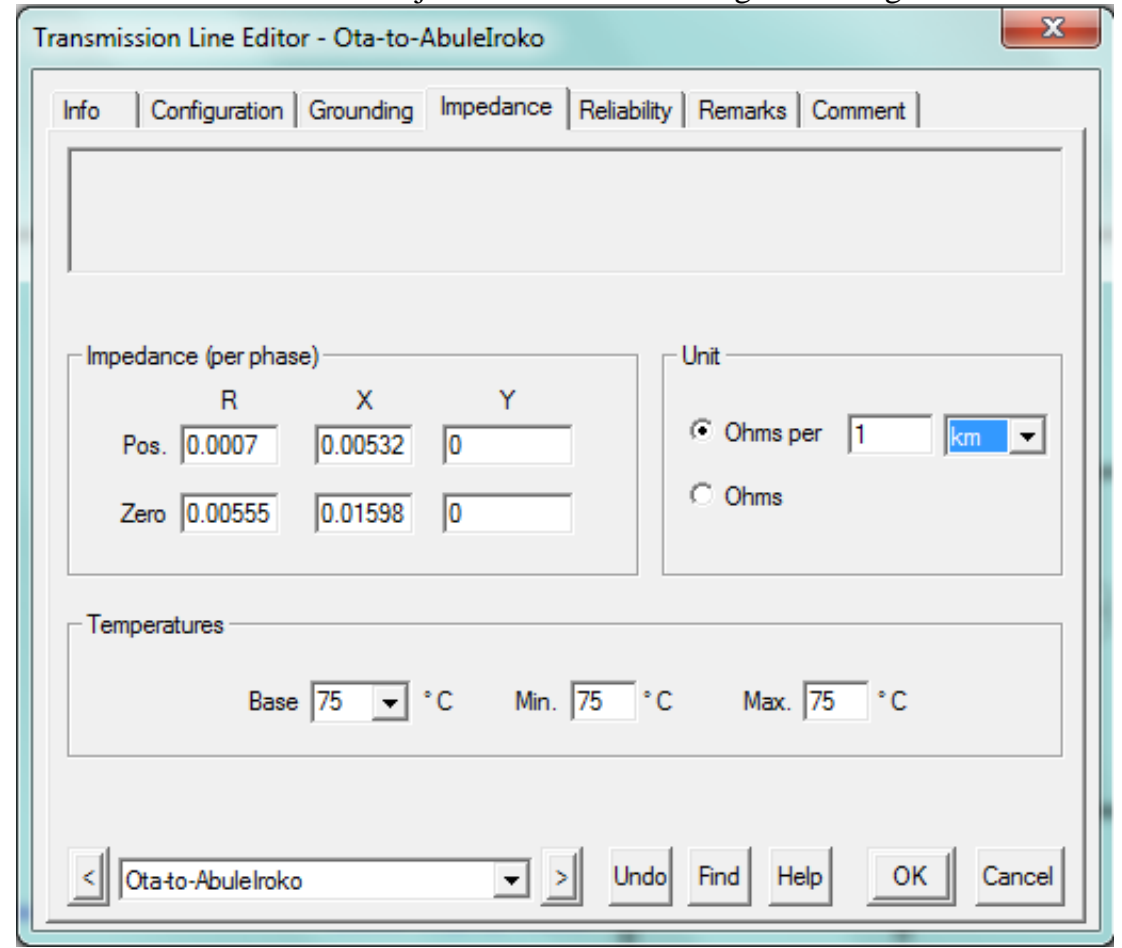

Figure 9: A window indicating the transmission line parameters which connects Ota transmission to Yusuf injection substation

\section{Modeling and Simulation of Abule-Egba Distribution}

As earlier said, the best method of studying a system is by making models and doing simulation. With simulation we can do changes in the model and see the result of changes. From the single-line diagram of fig.1 of the modeled distribution grid, the procedure adopted (starting from the top down) for the study is as follows:

- The power grid: This represents the network system up to the secondary distribution. It is set to swing mode because it makes up the difference between the scheduled loads and generated power [8].

- Next is the $33-\mathrm{kV}$ breaker with the following specifications:

Rated $\mathrm{kV}=36 \mathrm{kV}$ 
Making $=78.7$

Rated Amps $=2000 \mathrm{~A}$

FPC factor $=1.5$

AC breaking $=31.5$

Model $=$ OX

Manufacturer $=$ Alstom

$\lambda_{\mathrm{A}}=0.003$ Failure/year

$\lambda_{\mathrm{P}}=0.002$ Failure/year

$\mu=292$ Repair/year

$\operatorname{MTTF}$ (Mean time to failure $)=200$ years

MTTR (Mean time to repair) $=30$ hours

Switching time $=30$ hours

- Next is the transmission line which transmits electricity from the transmission station with its parameters as given below:

\begin{tabular}{|c|c|c|}
\hline Sequence & Resistance R $(\Omega / \mathrm{km})$ & Reactance X $(\Omega / \mathrm{km})$ \\
\hline Positive & 0.00953 & 0.7242 \\
\hline Zero & 0.07555 & 0.21753 \\
\hline
\end{tabular}

- After the transmission, is the $33-\mathrm{kV}$ bus-bar connected to Yusuf T1 a 33-/11-kV step- down transformer with the rating:

Primary voltage $=33 \mathrm{kV}$

Secondary voltage $=11 \mathrm{kV}$

Apparent power $=15 \mathrm{MVA}$

Maximum MVA $=15 \mathrm{MVA}$

Primary (Full load) Current $=262.4 \mathrm{~A}$

\begin{tabular}{l|ll} 
Sequence & $\mathbf{\% Z}$ & $\mathbf{X} / \mathbf{R}$ \\
\hline Positive & 7 & 18.6 \\
Zero & 7 & 18.6 \\
\hline
\end{tabular}

As seen from the above, the two injection sub stations which take their supply from Ota transmission are Yusuf 33/11KV injection s/s and AbuleIroko 33/11 injection s/s. Inside this substations are feeders which distribute the stepped- down power to various networks. Under Yusuf injection substation we have:

- Yusuf_11KV_feeder: This feeder feeds the community called Yusuf. Note that Yusuf injection substation lies within Yusuf community likewise the feeder which feeds the community lies within the substation.

- Agbefa_11KV_feeder: This feeder feeds the Agbefa community or distributes the stepped down voltage to Agbefa community.

We also have the AbuleIroko injection substation and under this substation are:

- Alakuko_11KV_feeder: This feeds Alakuko community or distributes the stepped down voltage to the Alakuko community

- AbuleIroko_11KV_feeder: Just as the Yusuf_11KV_feeder the AbuleIroko_11KV_feeder lies within AbuleIroko community and distributes electricity there.

- Books_11KV_feeder: Finally we have the Books feeder feeding Books community.

All the above mentioned feeders are modeled in ETAPS as composite networks which when double clicked opens up into a large network of distribution transformers and feeder pillars. A Typical sample model of this composite network is seen in Fig. 10 below and all other feeder pillars follow the same model pattern. 


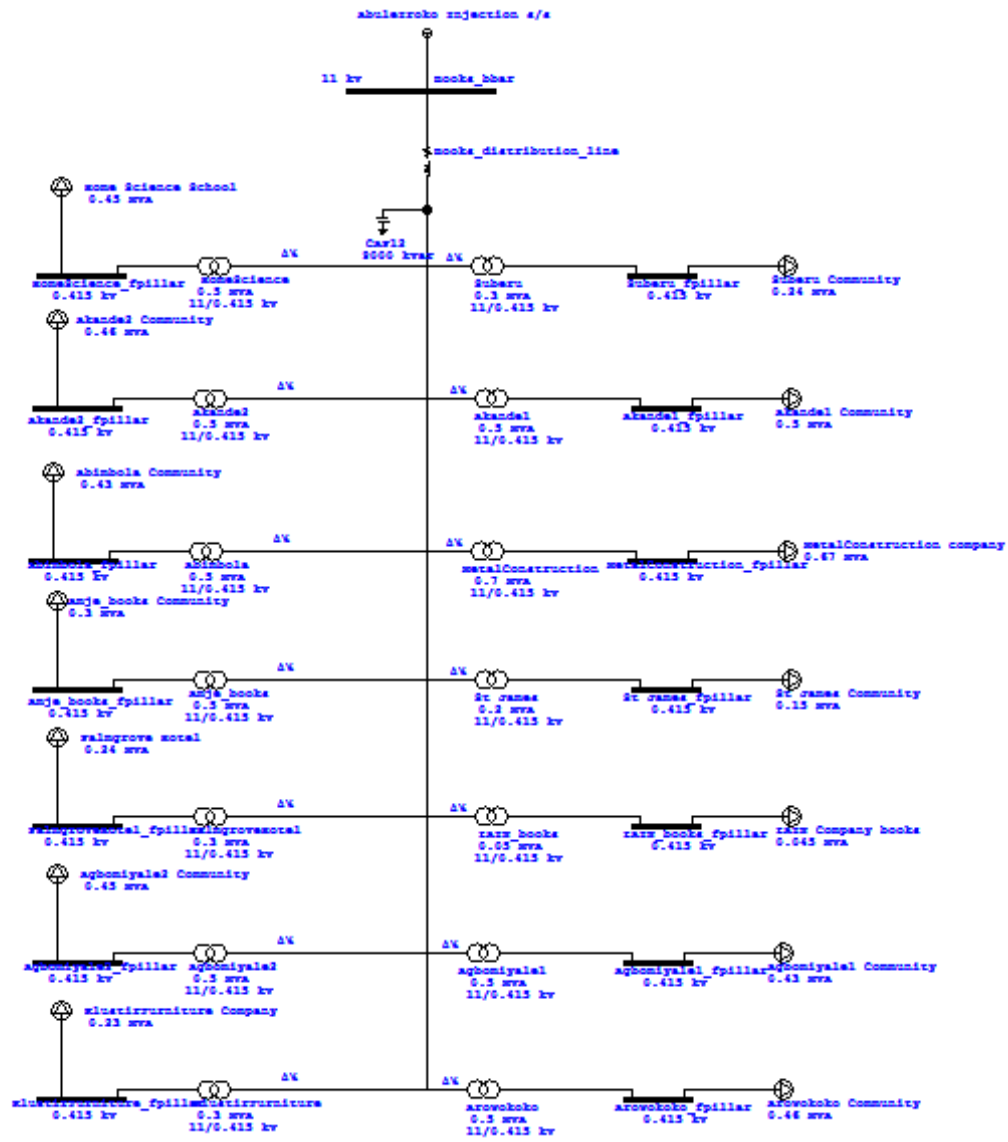

Figure 10: Books_11KV_feeder (A composite network of books community).

\subsection{Simulation: Load Flow Analysis}

Load flow analysis

Run load flow

Report manager

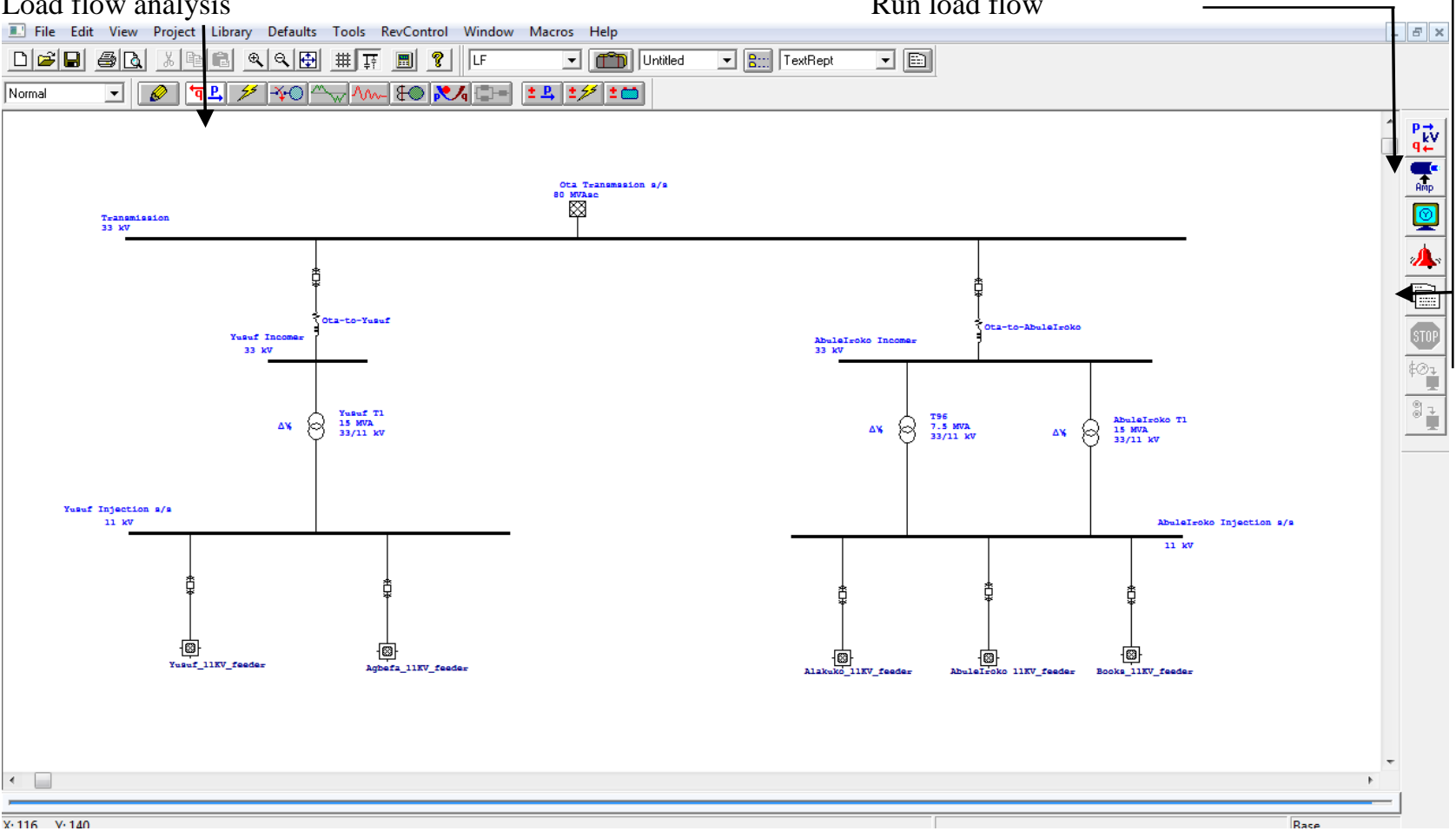

Figure 11: A diagram of the modeled distribution network ready for load flow

The diagram of the modeled distribution network ready for load flow is shown in Fig. 11 above. 


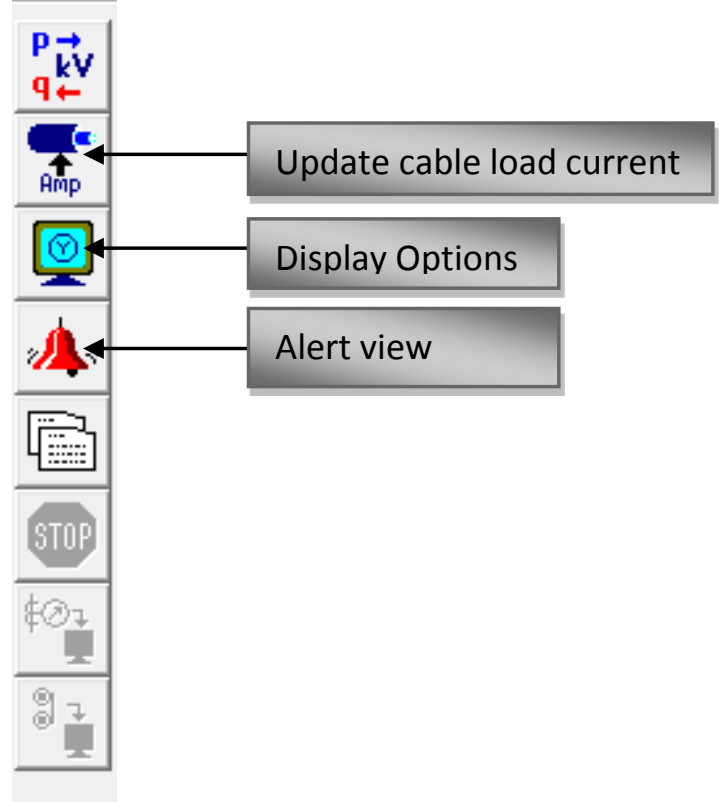

Figure 12: A diagram showing the respective tabs in the load flow analysis section.

Fig.12 above shows the diagram of the respective tabs in the load flow analysis section but before we click on the run load flow button, let's have a quick view of the display options and see what it entails.

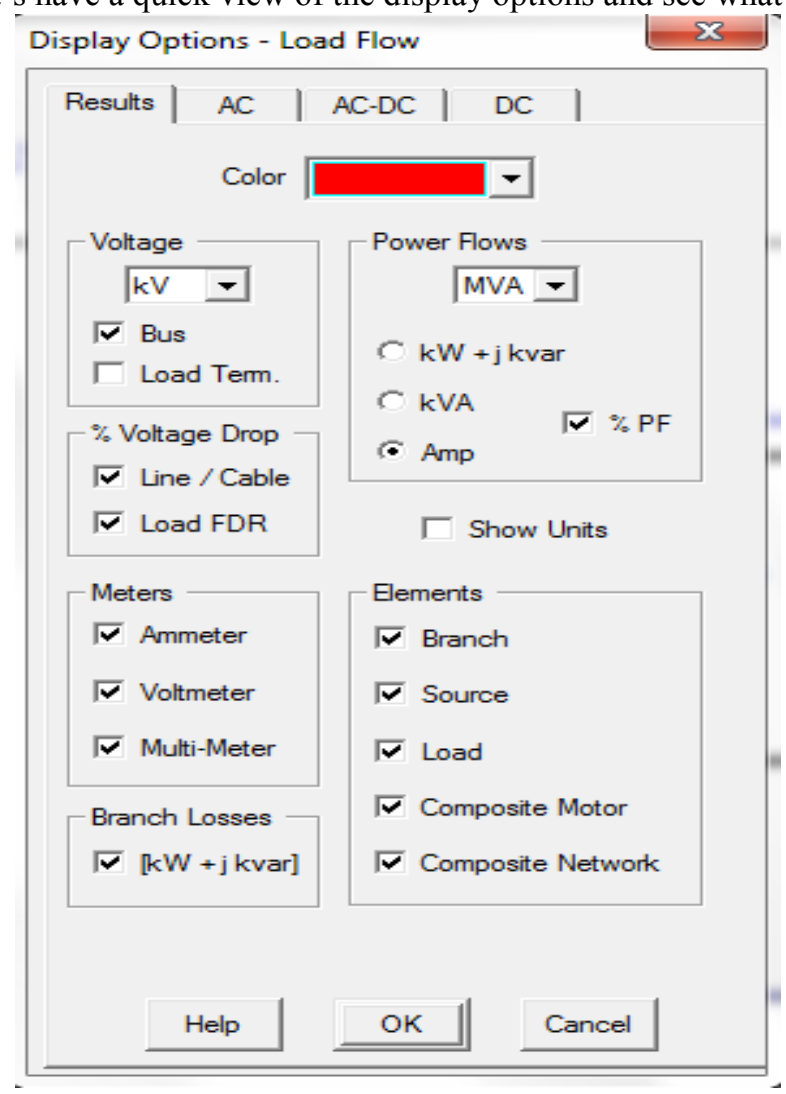

Figure 13: The display options window.

From Fig. 13 above we can see that the display option is divided into four tabbed sections.

- The results tab

- The AC tab

- The AC-DC tab

- The DC tab

For our analysis we will concern ourselves with the results tab and ticking an option is a pointer to what will be shown when the run load flow button is clicked. 


\section{Result Generation and Discussion}

The results tab presents options that can be edited and which can affect what is shown on the modeled diagram after the load flow analysis is carried out. With the default settings above and on running load flow, we obtain the following result:

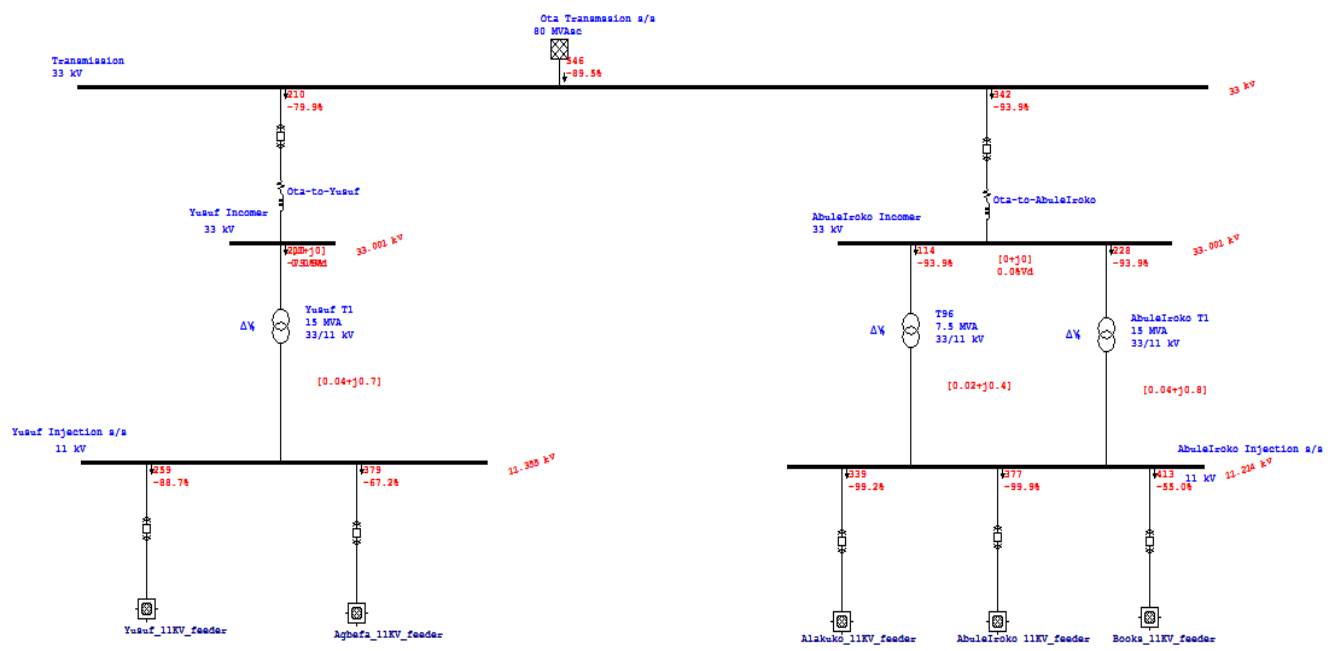

Figure 14: Result of the load flow.

From Fig. 14 above, the red indicates the result of the load-flow operation carried out on the distribution network.

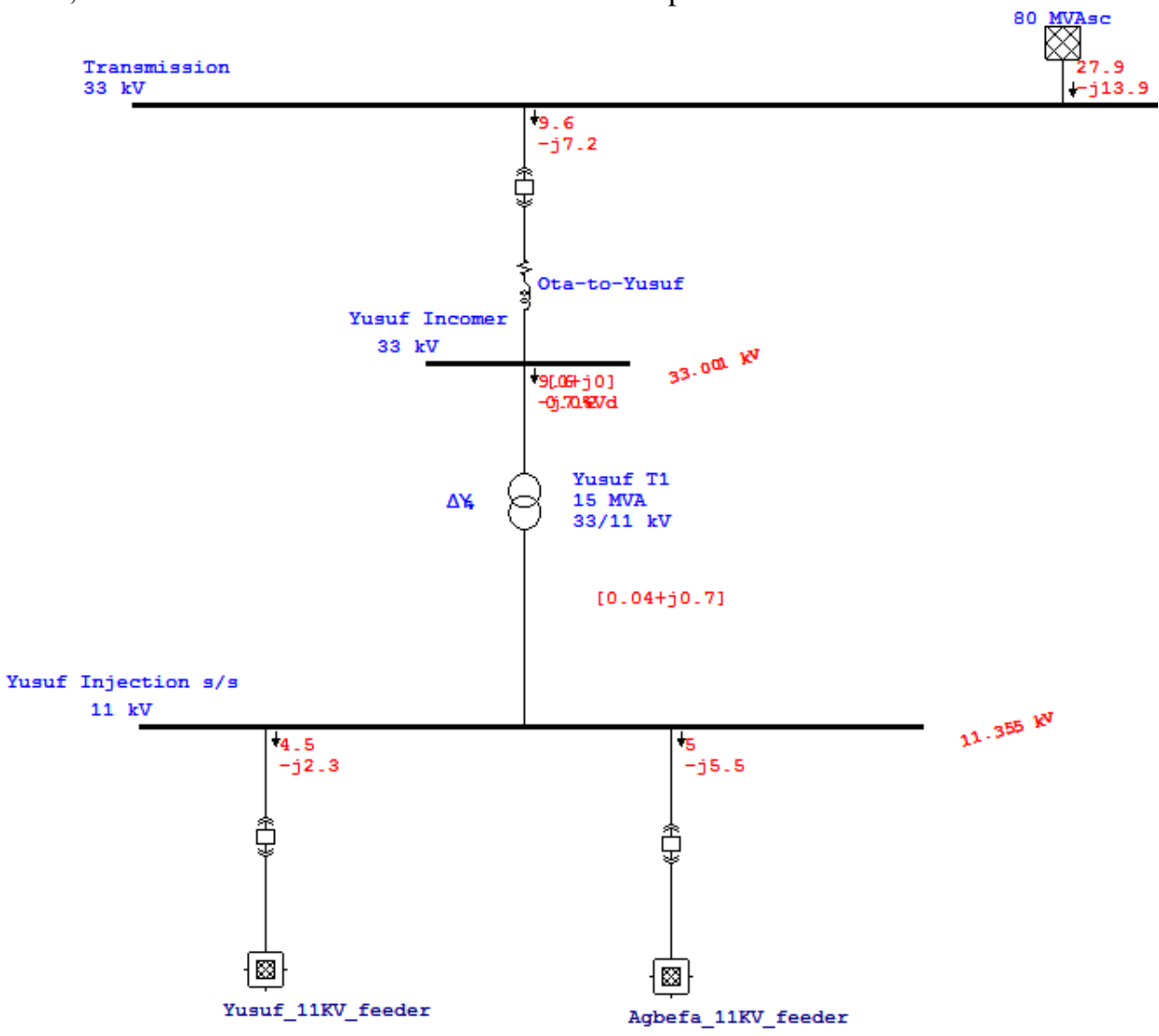

Figure 15: Results of the alteration in the display options windows.

We made our selection type in the power flows section $\mathrm{kW}+\mathrm{jkvar}$ and as seen from Fig 15, the real power supplied to Agbefa_11KV_feeder is 5MW while the reactive power is 5.5Mvar.

Further investigation/simulation on the network of Agbefa_11kV_feeder indicated that there is still need for compensatory works on some parts of this feeder. From fig. 16 below, we can see traces of pink shaded bus bar; this is a result of under voltage. Agbefa is not the only network affected as some other feeders have similar if not worse situations.For more detail as to the actual values of the under voltage of the networks we shall go into the alert view Fig. 17 to understudy this condition. 


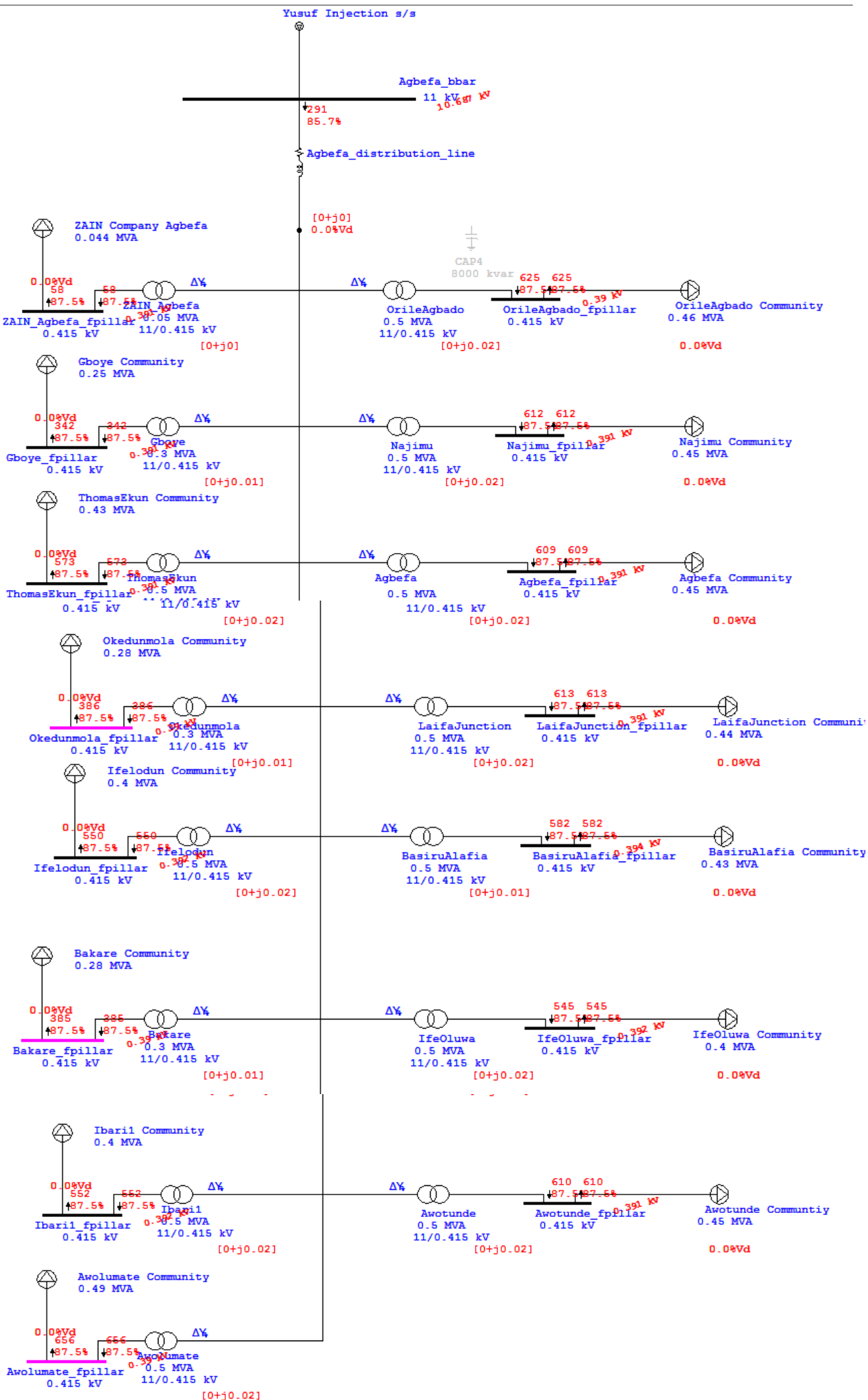

Fig 20: A simulation of the state of the Agbefa_11-KV_feeder with no capacitor banks. 
Power Flow Analysis of Abule-Egba 33-kV Distribution Grid System with real network Simulations.

\begin{tabular}{|c|c|c|c|c|c|c|c|}
\hline \multicolumn{6}{|c|}{ I. Load Flow Analysis Alert View - Output Report: Untitled } & \multicolumn{2}{|c|}{\begin{tabular}{|l|l|} 
& 0 \\
\end{tabular}} \\
\hline \multicolumn{5}{|l|}{ Study Case: LF } & Data Revision: & Base & \\
\hline \multicolumn{5}{|l|}{ Configuration: Normal } & Date: & \multicolumn{2}{|l|}{$04 \cdot 11 \cdot 2011$} \\
\hline \multicolumn{8}{|c|}{ Citicical } \\
\hline Device ID & Type & Rating & Calculated & \%Value & \multicolumn{3}{|l|}{ Condtion } \\
\hline Kollinton_fpillar & Bus & $0.415 \mathrm{KV}$ & 0.372 & 89.6 & \multicolumn{3}{|l|}{ UnderVoltage } \\
\hline \multicolumn{8}{|c|}{ Marginal } \\
\hline Device ID & Type & Rating & Calculated & \% Value & & a \\
\hline AGAS_FS_fpillar & Bus & $0.415 \mathrm{kV}$ & 0.389 & 93.7 & \multicolumn{3}{|l|}{ Undervoltage } \\
\hline Abarise_fillar & Bus & $0.415 \mathrm{kV}$ & 0.389 & 937 & \multicolumn{3}{|l|}{ Undervoltage } \\
\hline Abimbola_fillar & Bus & $0.415 \mathrm{kV}$ & 0.387 & 93.3 & \multicolumn{3}{|l|}{ Undervoltage } \\
\hline Ábulelroko_fillar & Bus & $0.415 \mathrm{kV}$ & 0.387 & 93.3 & \multicolumn{3}{|l|}{ UnderVoltage } \\
\hline Adebayoldowu_fillar & Bus & $0.415 \mathrm{kV}$ & 0.389 & 93.7 & \multicolumn{3}{|l|}{ UnderVoltage } \\
\hline Adebayo frillar & Bus & $0.415 \mathrm{KV}$ & 0.385 & 92.8 & \multicolumn{3}{|l|}{ UnderVollage } \\
\hline Adesanya_fpillar & Bus & $0.415 \mathrm{KV}$ & 0.396 & 93 & \multicolumn{3}{|l|}{ Undervoltage } \\
\hline AgbadaAyetoro_fillar & Bus & $0.415 \mathrm{kV}$ & 0.387 & 93.2 & \multicolumn{3}{|l|}{ Undervoltage } \\
\hline Agbomiyale1_fillar & Bus & $0.415 \mathrm{kV}$ & 0.387 & 93.4 & \multicolumn{3}{|l|}{ Undervoltage } \\
\hline Agboniyale2_fpillar & Bus & $0.415 \mathrm{kV}$ & 0.387 & 93.2 & \multicolumn{3}{|l|}{ Undervoltage } \\
\hline Aiejedun_fillar & Bus & $0.415 \mathrm{KV}$ & 0.378 & 91.2 & \multicolumn{3}{|l|}{ Undervoltage } \\
\hline Akande1_frillar & Bus & $0.415 \mathrm{kV}$ & 0.305 & 92.8 & \multicolumn{3}{|l|}{ Undervoltage } \\
\hline Akande2_fillar & Bus & $0.415 \mathrm{kV}$ & 0.386 & 93 & \multicolumn{3}{|l|}{ Undervoltage } \\
\hline Akande_fillar & Bus & $0.415 \mathrm{kV}$ & 0.389 & 93.7 & \multicolumn{3}{|l|}{ Undervoltage } \\
\hline Alice0latoun_fpillar & Bus & $0.415 \mathrm{kV}$ & 0.387 & 93.3 & \multicolumn{3}{|l|}{ Undervoltage } \\
\hline Amie_fillar & Bus & $0.415 \mathrm{kV}$ & 0.387 & 93.2 & \multicolumn{3}{|l|}{ Undervoltage } \\
\hline Anuoluwapo_fillar & Bus & $0.415 \mathrm{KV}$ & 0.388 & 93.4 & \multicolumn{3}{|l|}{ Undervoltage } \\
\hline AraromiEstate_fpillar & Bus & $0.415 \mathrm{KV}$ & 0.387 & 93.3 & \\
\hline Arilie1_fpillar & Bus & $0.415 \mathrm{KV}$ & 0.387 & 93.3 & \multicolumn{3}{|l|}{ Undervoltage } \\
\hline
\end{tabular}

Figure 17: The alert view showing the condition of the various feeder pillars that underwent under voltage.

Based on PHCN power factor of 0.85 [9] for the Abule_Egba distribution lines, the KVar capacities of the various capacitors required to carry out full compensation of the network were determined.

\section{Agbefa_11-kV Feeders}

Total real load Power $=\quad 5.5 \mathrm{MW}$

Power factor $=\quad 0.85$

Reactive KVAr of load $=\quad \frac{5.5}{0.85}\left(\sin \left(\cos ^{-1} 0.85\right)\right.$

$=3408.6 \mathrm{KVAr}$

Reactive KVAr of load corresponding to $0.95 \mathrm{pf}$

$$
\begin{aligned}
& =\frac{5.5}{0.95}\left(\sin \left(\cos ^{-1} 0.95\right)=\right. \\
& =1807.8 \mathrm{KV} \text { Ar lagging }
\end{aligned}
$$

Rating of capacitor bank $=3408.6-1807.8 \mathrm{KVAr}$

$$
=1600.8 \mathrm{KVAr}
$$

The size corresponds to value obtained from table (BICC1965) for determining sizes of capacitor in KVAr per $\mathrm{KW}$ of load of raising the power factors. Thus, using the table, the capacitor bank rated CAP4 8000KVAr was selected. With the connection of this capacitor size, all the pink shaded bus voltage violations were regulated as shown in the generated result of fig. 18 . 


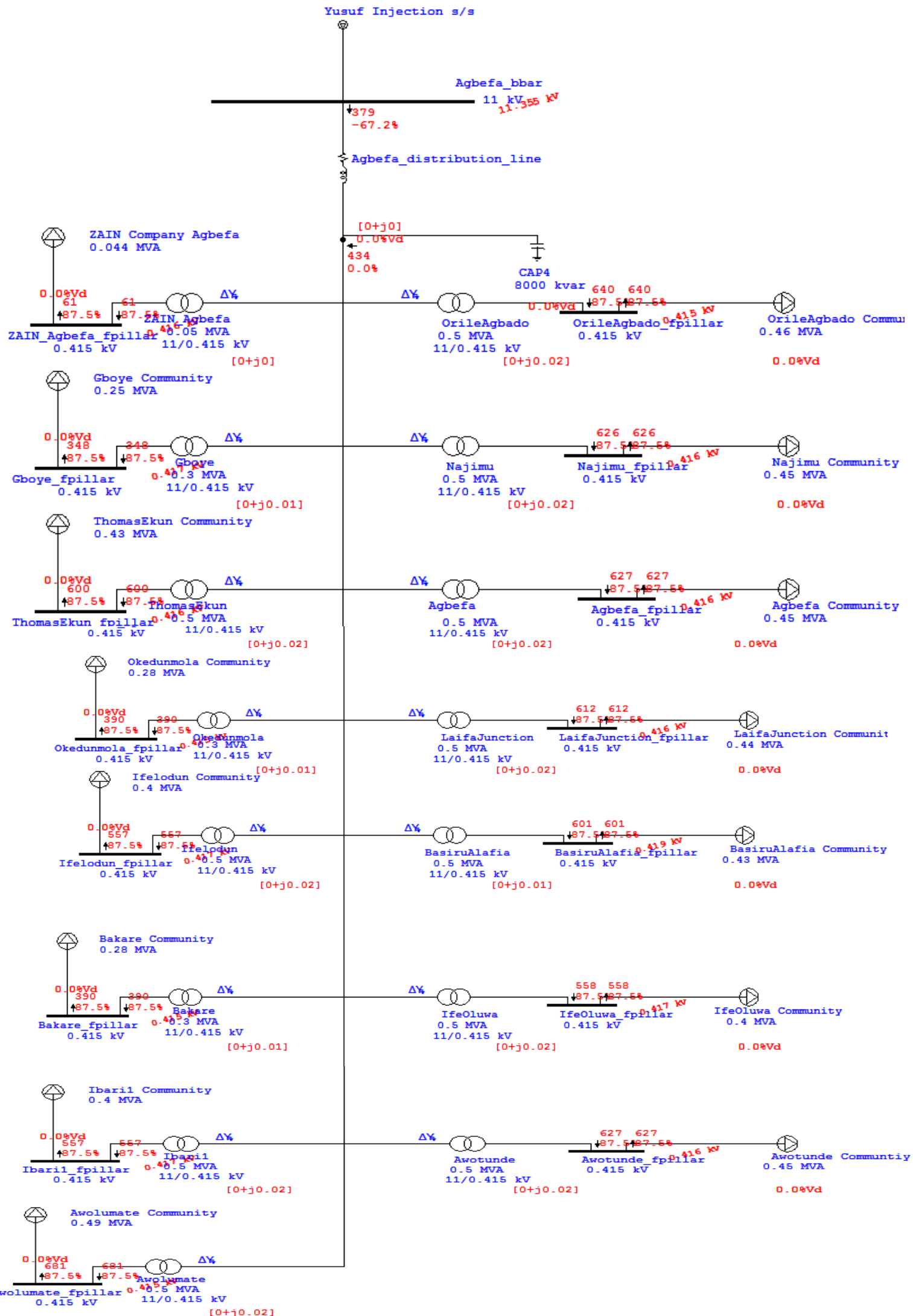

Fig 18: A simulation of the state of the Agbefa_11KV_feeder with capacitor bank rated CAP4 8000KVAr connected.

The result obtained with the introduction of this rating of capacitor bank regulate the voltages, showing by the traces of pink shaded buses at various feed points to the distribution transformers as revealed in fig 18 above. 


\section{Conclusion and Recommendation}

Although this study does not represent the entire ABULE - EGBA Distribution 33-kV grid it surely provides mimicry of the entire network. The very low bus voltages and poor power magnitude obtained from this study without voltage compensation at Agbefa_11KV Feeder revealed the reality of the epileptic poor power supply at the Abule - Egba part of Lagos state, Nigeria. In order to augment this disturbing situation, it is recommended that relevant stake holders imbibe the reduction of power loss in distribution Networks via correct sizing and location of reactive power support. If not properly applied or sized, the reactive power from capacitor banks can create even more losses and high voltages that can damage light load. Moreover, the investments needed for the introduction of capacitor bank at appropriate locations are smaller compared to those required for the construction of new lines.

\section{Acknowledgment}

The authors are grateful to PHCN for providing relevant data used in the study. We also sincerely appreciate the contribution of the entire staff of ABULE - EGBA Distribution grid.

\section{Reference}

[1]. O.S. Onohaebi, Power system analysis; M.Eng lecture notes, Department of electrical engineering, University of Benin, Benin-City, Edo state, Nigeria.

[2]. D. Das, P. Kaothari and A. Kalam, Simple and efficient methods for load flow solution of radial distribution system, Electrical Power and Energy Systems, 17(5), 1995, 335-346.

[3]. M. S. Bhailla, Proceedings of National conference and regulation in infrastructure services, New Delhi, India, 2000.

[4]. Power Holding Company of Nigeria (PHCN) Plc, 2006, One-line diagram of Abule-Egba distribution network.

[5]. I. Boldea, Synchronous generators (Electrical power engineering series, 2005)

[6]. J.B.V. Subrahmanyam, Load flow solution of unbalanced radial distribution systems, Department of electrical and electronics engineering, BRECN, Hyderabad, India 500 059, 2005-2009.

[7]. D. Shimohammadi and C. S. Cheng, A three-phase power flow for real time distribution system analysis, IEEE Trans on power system, 10(2) 1995

[8] H. Saddat, Power System Analysis, second edition, 2004, pg 225-227

[9] Power Holding Company of Nigeria (PHCN)Plc, Power factor for Abule-Egba distribution grid 